\title{
A Double-blind Placebo-controlled Multicenter Phase 2 Trial to Evaluate D- methionine in Preventing/Reducing Oral Mucositis Induced by Radiation and Chemotherapy for Head and Neck Cancer.
}

Daniel A. Hamstra, MD, $\mathrm{PhD}^{1^{*}}$, Kuei C. Lee, MD, $\mathrm{PhD}^{1}$, Avraham Eisbruch, $\mathrm{MD}^{2}$, Prasad Sunkara, PhD $^{5, \dagger}$, Sudhir Borgonha, MD, 6,@, Babu Phillip, MD ${ }^{7}$, Kathleen C.M. Campbell, $\mathrm{PhD}^{8}$, Brian D. Ross, $\mathrm{PhD}^{3,4,5}$, and Alnawaz Rehemtulla. $\mathrm{PhD}^{2,5}$

The Department of Radiation Oncology. Beaumont Health, Dearborn, $\mathrm{MI}^{1}$, The Department of Radiation Oncology ${ }^{2}$, Radiology ${ }^{3}$, and Biological Chemistry ${ }^{4}$. The University of Michigan, Ann Arbor, MI. Molecular Therapeutics Inc. Ann Arbor, $\mathrm{MI}^{5}$, Clinical Evaluation and Testing Services, Bangalore, India ${ }^{6}$, St. John's Medical College, Bangalore, India ${ }^{7}$, The Department of Medical Microbiology, Immunology and Cell Biology, Southern Illinois University School of Medicine, Springfield, $\mathrm{IL}^{8}$

* To Whom Correspondence Should Be Addressed:

Daniel A. Hamstra, MD, PhD

The Department of Radiation Oncology

Beaumont Health, Dearborn

Dearborn, MI 48124

Ann Arbor, MI 48109-5010

Phone: 248-551-7058

e-mail: Daniel.Hamstra@Beaumont.org

†Current Address:

Innova Therapeutics, Inc

1363 Caminito Diadema

La Jolla, CA 92037

(a) Current Address:

Strand Life Sciences

Bangalore, India

Running Title: $\quad$ Phase 2 Study of D-Methionine to Prevent Mucositis

Abbreviations: D-met, D-methionine, L-met, L-methionine, MRX-1024, A proprietary orally available suspension of D-met, OM, oral mucositis, SCCHN, Squamous cell carcinoma of the head and neck, AUC, area under the concentration vs. time curve, Cmax, peak concentration, KPS, Karnofsky performance status, IQR, inter-quartile range, CDDP, cisplatin, SD, standard deviation, SEM, standard error of the mean, $\mathrm{PF}$, protective factor.

This is the author manuscript accepted for publication and has undergone full peer review but has not been through the copyediting, typesetting, pagination and proofreading process, which may lead to differences between this version and the Version of record. Please cite this article as doi:10.1002/ hed.25115. 
Phase 2 Study of D-Methionine to Prevent Mucositis

\section{Financial Disclosures:}

- This study was funded by a grant from Molecular Therapeutics Inc. (Ann Arbor, MI) to Nizam's Institute of Medical Sciences (Hyderabad, India), The IndoAmerican Cancer Institute and Research Center (Hyderabad, India), The Curie Center of Oncology, St. John's Medical College (Bangalore, India), The Karnatak Cancer Therapy and Research Institute (Hubli, India), and St. John's Medical College (Bangalore, India)

- B.D.R, and A. R. had a financial interest in Molecular Therapeutics Inc. which has now been disincorporated and were responsible for providing research funding, study design, data analysis, and manuscript preparation.

- P.S. was employed by Molecular Therapeutics Inc and was responsible for study design, data analysis, and manuscript preparation.

- S.B. was a paid consultant for Molecular Therapeutics Inc. and employed by Clinical Evaluation and Testing Services, Bangalore, India. He was responsbile for on-sight data management, study design, analysis, and manuscript preperation.

- K.C.M.C. and Southern Illinois University hold a patent on the use of Dmethionine to decrease normal tissue toxicity. She was responsible for study design and manuscript preparation.

- A.E. acted as a paid consulted to Molecular Therapeutics Inc.. He was involved with study design, data analysis, and manuscript preparation.

- K.C.L. has no financial disclosures and was involved with manuscript preparation.

- B.P. worked funded through a grant to St John's Medical College and was involved with study design, clinical care of patients, and manuscript preparation.

- All data was available to D.A.H. who had no financial interest in the studies outlined. He who was responsible for data analysis and preparation of this manuscript as well as for the final revision of the manuscript.

- Thanks to the following physicians for their role in treating patients on this trial: Maddireddy U. R. Naidu, The Department of Clinical Pharmacology and Therapeutics Nizam's Institute of Medical Sciences (Hyderabad, India); M. VidyaIndo-American Cancer Institute and Research Center (Banjara Hills, 
Phase 2 Study of D-Methionine to Prevent Mucositis Hyderabad, India). G. Kilara, The Curie Center of Oncology, St. John's Medical College (Bangalore, India), and Akhil Chandra Deka, Karnatak Cancer Therapy and Research Institute (Navanagar, Hubli, India) as well as to Morris Groves for

statistical analysis.

John Wiley \& Sons, Inc. 
Phase 2 Study of D-Methionine to Prevent Mucositis

\section{Abstract}

Background: To test if oral D-methionine (D-met) reduced mucositis during chemoradiotherapy.

Methods: Placebo controlled double-blind randomized Phase 2 trial of D-met (100 $\mathrm{mg} / \mathrm{kg}$ po BID) testing the rate of severe (grade 3-4) mucositis.

Results: Sixty patients were randomized. Grade $2+$ oral pain was higher with placebo (79\% vs. $45 \%, \mathrm{p}=0.0165)$ while grade $2+$ body odor was greater with $\mathrm{D}$-met $(3 \%$ vs. $41 \%, p=0.0015$ ). Mucositis was decreased with D-met by physician (WHO, $p=0.007$, RTOG, $p=0.009$ ) and patient functional scales (RTOG, $p=0.0023$ ). The primary endpoint of grade 3-4 mucositis on the composite scale demonstrated a decrease with D-met (48\% vs. $24 \%, p=0.058)$ which was borderline in significance. A planned secondary analysis of a semi-quantitative scoring system noted decreased oral ulceration (2.2 vs. $1.5, p=0.023)$ and erythema (1.6 vs. $1.1, \mathrm{p}=0.048)$ with D-met.

Conclusions: Although not meeting the primary end-point, results of multiple assessments suggest that D-met decreased mucositis.

$147 / 150$ words

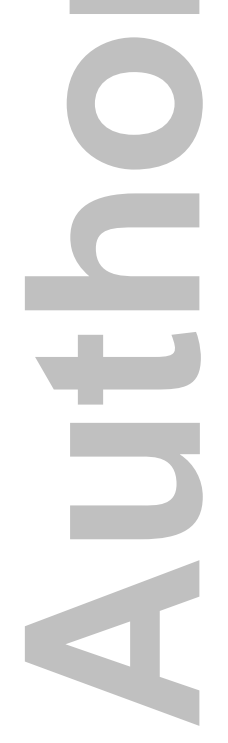


Phase 2 Study of D-Methionine to Prevent Mucositis

\section{Statement of Translational Relevance}

Mucositis is a common dose-limiting side-effect of radiation therapy in head and neck cancer patients. To date no clear treatment that mitigates this toxicity for this patient population has been routinely adopted. Previously it was demonstrated that Dmethionine (D-met) could protect non-transformed human cells in culture from radiation induced cell death while not similarly protecting tumors cells. In addition, a phase I trial demonstrated the safety and bioavailability of oral D-met with a suggestion of decreased mucositis compared to historical controls. Here we demonstrate in a multi-institutional randomized placebo controlled phase 2 trial that D-met had no significant increased toxicity but was associated with decreased oral mouth pain and mucositis for patients treated with concurrent RT and cisplatin for SCCHN.

Summary : 120 words.

Manuscript: 4854 words
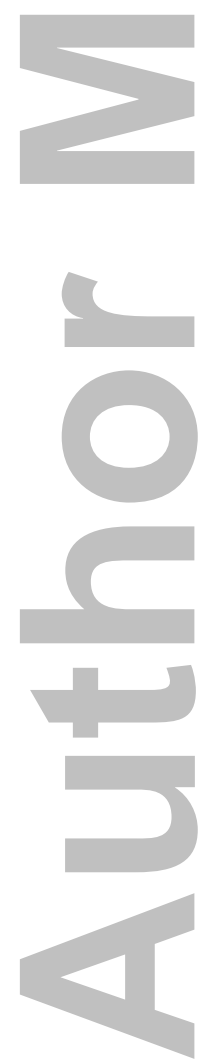
Phase 2 Study of D-Methionine to Prevent Mucositis

\section{Introduction}

In the U.S., approximately 49,670 patients in 2017 will be newly diagnosed with cancers of the head and neck, and approximately 9,700 will die from this disease(1). The combination of chemotherapy and radiotherapy (ChemoRT) is commonly utilized in patients with squamous cell cancers of the head and neck (SCCHN). Oral mucositis (OM) is a dose-limiting side-effect of chemoRT which is characterized by mucosal erythema and ulceration often with secondary bacterial or fungal infections with severe OM occurring in $40-80 \%$ of patients(2). A wide range of different therapies have been evaluated for OM including: antimicrobials(3,4), cytokines(5-8), keratinocyte growth factor(9), anti-inflammatories(10-12), coating rinses(13), honey(14-17), glutamine(18), cryotherapy(19), and laser treatment(20). The microbial make-up of the oral cavity has also been noted to influence the development of mucostiis with the flora within the oral cavity or the cytokine response prognostic for $\operatorname{OM}(21,22)$.

D-methionine (D-met) is the dextro isomer of the essential amino acid, L-methionine; while MRX-1024 is a high-concentration (200 $\mathrm{mg} / \mathrm{ml})$ bio-available suspension formulation of D-met (Molecular Therapeutics Inc, Ann Arbor, MI). D-methionine is a natural micronutrient with both the $\mathrm{D}$ - and L-isomers present in high-concentrations in a normal diet. Due to minimal human catabolism D-met results in higher plasma levels than L-met with $>60 \%$ of D-met excreted without conversion (23-26). Clinically, L-met has been available for decades for treatment of dermatitis (200-400 mg po TID-QID) while the racemic mixture has been used to treat acetaminophen overdose $(10 \mathrm{~g}$ po over $12 \mathrm{hr}$ ).(27-31) The most common side-effect of oral methionine is nausea.

D-methionine was previously demonstrated in animal models to protect against oxidative stress associated ototoxicity and nephrotoxicity from cisplatin, aminoglycosides, or noise related injury.(32,33) D-methionine also protected non-transformed human cells (fibroblasts, keratinocytes, and endothelial cells) from RT associated cell death with a protective factor in clonogenic assays of 1.2-1.6. Notably, radiation protection was not observed in transformed human tumor cell lines in vitro or in vivo.(34) Fractionated irradiation of mouse oral mucosa for 5 days resulted in higher peak mucositis in control animals compared to animals pre-treated with D-met with a dose dependent increase in 
radiation protection from 200,300 , and $500 \mathrm{mg} / \mathrm{kg}$ yielding protective factors of 1.6, 2.1, and 2.6, respectively $(\mathrm{p}<0.0003)$.(34) More recently others demonstrated protection from radiation injury with D-met in mouse and zebra fish models. $(35,36)$

The long clinical use of D-met plus the pre-clinical data showing protection from mucosal injury led to a previously reported Phase I clinical trial where 25 patients with SCCHN were treated with fractioned RT (with 78\% also receiving cisplatin)(37). Pharmacokinetic analysis revealed that when administered orally at $100 \mathrm{mg} / \mathrm{kg}$, peak and area under the curve (AUC) levels of D-met were comparable to the levels previously associated with mucosal protection in rodents. There was a modest increase in nausea/vomiting following D-met with 5 patients withdrawing from the study due to nausea and emesis, but only $1(1 / 25,4 \%)$ incidence of dose limiting toxicity (grade 3 emesis). Only one in 18 patients $(6 \%)$ had grade 3 mucositis with no grade 4 mucositis.

We report here a randomized controlled Phase 2 trial of orally administered D-met along with concurrent weekly cisplatin and radiotherapy for SCCHN involving the oral cavity and/or oral pharynx.

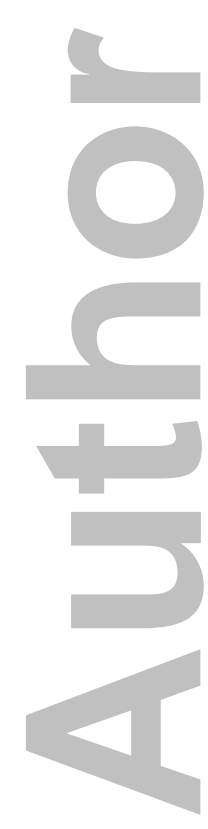


Phase 2 Study of D-Methionine to Prevent Mucositis

\section{Materials and Methods}

\section{Trial Design}

After local IRB approval a double blind placebo controlled clinical trial was performed at 4 institutions in India (See Figure 1, Supplemental Table 1). Patients were to have newly diagnosed cancers of the head and neck with a plan to receive concurrent cisplatin and radiotherapy (minimum $60 \mathrm{~Gy}$ in conventional fractions) to at least $50 \%$ of the oral cavity, oral pharynx, or both. Following informed consent and enrollment patients were randomly assigned to one of two treatments (D-met or placebo) in a 1:1 ratio using a computer-generated algorithm stratified by center using a fixed block size.

\section{Radiation Therapy}

Treatment was with either a ${ }^{60}$ Co teletherapy unit or linear accelerator $(\geq 4 \mathrm{MeV})$ using either 2D or 3D based CT-planning. No intensity modulated radiotherapy was used. Portal margins were shaped using cerrobend blocks or a multileaf collimator. Compensators or wedges were used to assure dose homogeneity that was $\pm 5 \%$ of the midplane central axis dose. Opposed photon portals were used while wedge pair techniques that spare mucosa on one side were excluded except when used to boost the primary tumor after delivery of a minimum dose of $60 \mathrm{~Gy}$. The administration of radiation was such that the oropharyngeal mucosa was planned to receive a central axis midplane dose of 60-70 Gy over 6-7 weeks, 1.8 to 2.0 Gy once a day.

\section{Cisplatin}

All patients entering the study were medically appropriate to receive cisplatin which was administered intravenously (50 mg per week) after the patient received the RT scheduled for that day. This was on average $28 \mathrm{mg} / \mathrm{m}^{2}$ and reflected the common practice. Patients were hydrated with normal saline administered intravenously (500-1500 ml over 3-4 hours). All patients receiving cisplatin were to receive an antiemetic regimen sufficient to ameliorate this expected adverse event with 4-16 mg of ondansetron plus 5-20 $\mathrm{mg}$ of dexamethasone recommended; variation was allowed by institution. 
Phase 2 Study of D-Methionine to Prevent Mucositis

\section{Study Drug}

The active pharmaceutical ingredient in MRX-1024, manufactured by stereo-specific chemical synthesis according to cGMP guidelines, is D-methionine (CAS Registry Number 348-67-4, manufactured by Natco Pharma Ltd, Banjara Hills, Hyderabad, India).

Supplies of D-met or placebo were provided in identical amber bottles with the same labels, buffered solution, and flavoring. Patients, physicians, or study personnel responsible for preparing individual doses or for evaluating patient outcomes were unable to distinguish D-met from placebo.

\section{D-methionine - Method of Administration}

D-met $(200 \mathrm{mg} / \mathrm{ml})$ or placebo were stored at controlled ambient room temperature. The amount to be administered was based upon the patient's body weight in the preceding week at a dose of $100 \mathrm{mg} / \mathrm{kg}$ BID. The suspension was measured out by study personnel and the patients ingested the drug in their presence. No attempt to swish, swallow, or gargle the suspension was recommended or required. Patients were not allowed to selfmedicate. Based upon pre-clinical data the first dose was to be taken 30-60 minutes prior to RT and the second 30-60 minutes post-RT daily.(34) The drug was not taken on days when radiation was not delivered. Patients should not have consumed anything by mouth (other than water and scheduled medications) for one hour prior to receiving study drug.

\section{Study Assessments, Visit Schedule}

Potential study participants were screened versus the inclusion and exclusion eligibility criteria which are provided in Supplemental Table 1. All patients had to have head and neck cancer with a plan to deliver concurrent cisplatin and radiotherapy. Eligible and consenting patients completed a baseline evaluation that included a physical examination with an oral examination, medical history, vital signs, blood collection for specified laboratory tests, and when appropriate a serum pregnancy test.

Patients were seen according to the following schedule: a screening visit (-21 to -1 day prior to treatment), baseline (before first dose of drug on Day 1), during treatment (at the end of the week for each of 6-7 planned weeks of ChemoRT with the last appointment 
Phase 2 Study of D-Methionine to Prevent Mucositis

after the last dose of drug was taken), and then 30 days after the end of treatment. Patients had weekly complete blood count (CBC) and comprehensive metabolic panel. Toxicities were evaluated by CTCAE version 3.0 at each planned visit.

Adverse events were documented at each study visit. Oral mucositis was assessed as indicted below. All patients who received at least one dose of study drug and one fraction of RT were considered evaluable and included for analysis. The last follow-up per protocol was 30 days post treatment with no extended follow-up planned

Initially an analysis of patient reported outcomes with the FACT-H\&N instrument was planned; however, due to a lack of validated instruments in several of the local dialects this aim was discontinued.

\section{Adverse Events (AE)}

Investigators, blinded to the assigned study medication being received by each patient evaluated each reported $\mathrm{AE}$ for the likelihood that the event was attributable to the study medication (D-met/placebo). The Investigators judged AE as being Definitely, Probably, Possibly, Not Likely, or Unrelated to the study medication.

Serious Adverse Events (SAE) were reported to the local IRBs and were defined as an AE that met any of the following:

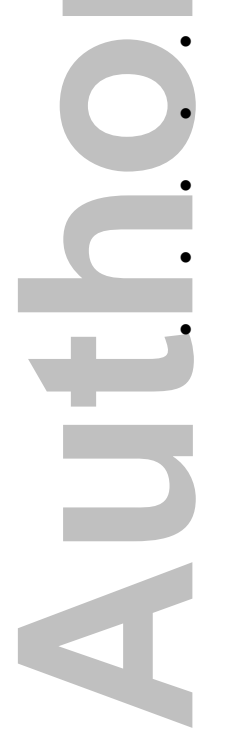

Death;

Life-threatening;

Persistent or significant disability and/or incapacity;

Required inpatient hospitalization;

Other medically significant event that may jeopardize the patient and may require medical or surgical intervention to prevent one of the outcomes listed above.

\section{Objectives:}


The primary objective was to determine the efficacy of orally administered Dmet in reducing the percentage of patients who develop serious (Grade 3 or 4) oral mucositis.

\section{Planned secondary objectives included:}

- To determine if patients receiving D-met experience fewer complications normally associated with the development of oral mucositis compared to patients receiving placebo, specifically fewer hospitalizations for infection, less weight loss during treatment, less opioid analgesic consumption, and fewer days receiving parenteral nutrition;

- To determine if patients receiving D-met were able to complete their radiation and chemotherapy treatment sooner than patients receiving placebo;

- To determine if patients receiving D-met obtained a similar antitumor response to radiation and chemotherapy as patients receiving placebo.

\section{Oral Mucositis Assessments}

Study personnel at each site were trained in standardized mucosal evaluations prior to opening the study. At each visit (see Figure 1), study personnel examined the oral cavity and recorded results using each of four methods for assessing oral mucositis. These included the World Health Organization (WHO) grading scale for mucositis (Supplemental Table 2), The Radiation Therapy Oncology Group (RTOG) Oral Mucositis Grading System: Gross Physician Rating (Supplemental Table 3), the RTOG Functional Patient Rating (Supplemental Table 3), and the Objective Scoring System for Site Assessment (OSSFA, Supplemental Table 4)(38).

\section{Assessment of Tumor Response}

Each patient had a CT scan of the head and neck performed within 15 days prior to beginning treatment and again 30 days after receiving their last dose of radiotherapy. The CT scans were reviewed by an independent radiologist (B.P.) at the completion of the study who was blinded to treatment allocation. The mass lesions from the baseline 
Phase 2 Study of D-Methionine to Prevent Mucositis

and follow-up CT scans were recorded and their measurements used to stratify patients by RECIST criteria.

\section{Sample Size and Statistical Plan}

Patients with SCCHN receiving treatment with ChemoRT were anticipated to have $70 \%$ incidence of severe (Grade 3 or Grade 4) oral mucositis. Based on the Phase 1 trial of MRX-1024 this was estimated at $10 \%$ in the experimental arm. Using a power of 0.9 and a significance level of 0.01 , required a total of 40 evaluable patients; 20 per arm. Historical data within India suggested that a higher number of patients should be enrolled to account for non-completing patients due to economic, social, cultural or other reasons. For this reason, a sample size of 60 patients, 30 patients per arm, was selected in order to achieve 40 evaluable. The study was powered for the primary but not for the secondary objectives.

The statistical analysis plan, determined prior to unmasking of the randomization code, established the primary end-point as the proportion of patients experiencing Grade 3 or greater OM using a composite of the highest score noted during treatment using the WHO and the 2 RTOG scales. Secondary analyses were planned per protocol while unplanned secondary analyses were performed as indicated in a post hoc manner.

The protective effect of D-met was measured based upon cumulative mucositis and peak mucositis measurements using the area under the time mucositis curve (AUC) which was calculated using PK Functions for Microsoft Excel, a series of Add-in functions for Excel spreadsheets, designed and written by Joel I. Usansky, Atul Desai, and Diane Tang-Liu (Department of Pharmacokinetics and Drug Metabolism, Allergan, Irvine, CA). All other statistical analysis was performed with MedCalc Statistical Software version 17.2 (MedCalc Software bvba, Ostend, Belgium; http://www.medcalc.org; 2017). All pvalues of $<0.05$ were considered statistically significant without correction for multiple comparisons. 
Phase 2 Study of D-Methionine to Prevent Mucositis

\section{RESULTS}

\section{Treatment Plan}

The first patient was enrolled on July 29, 2005 and the last on March 17, 2006. All patients have completed their participation on this protocol. Eligible and consenting patients were randomized 1:1 to receive either MRX-1024 (an oral suspension of Dmethionine) or a placebo. Treatment with the combination of radiation, cisplatin, and Dmet/placebo continued until a total of 60-70 Gy of radiation was administered over 6 to 7 weeks, or until the patient terminated treatment for any reason.

\section{Demographics}

There were no differences between treatment arms in any clinical or demographic criteria (Table 1). All patients were of Indian ancestry with 76\% male, median age of 51 years, a median KPS of 90 , and $>95 \%$ with squamous cell carcinoma (with 3 cases of poorly differentiated carcinoma) with involvement of the oral cavity $(90 \%)$ and/or oropharynx (10\%). Forty-five percent of patients had stage group III/IV disease with $15.5 \%$ with positive lymph nodes.

\section{Treatment}

The treatment delivered is outlined in Table 2. Median number of radiation fractions delivered was 31 with no difference between arms with a median total dose 62 Gy in 1.8$2.0 \mathrm{~Gy}$ fractions. There was no difference in the type of radiation equipment utilized

(Linac vs. ${ }^{60} \mathrm{Co}, \mathrm{p}>0.5$ ). Patients on the placebo arm did take longer to complete all treatment (median 48 vs. 42 days, $\mathrm{p}=0.05$ ). On both arms $86 \%$ of patients received at least one dose of cisplatin with the median number of weekly cycles on each arm being 4 . The median doses of study drug delivered was 62 which was slightly higher for placebo (64) as compared to control $(60, \mathrm{p}=0.096)$.

\section{Adverse Events, Patient Withdrawals, and Deviations.}

Overall 30 patients were randomized to each arm ( $n=60$ total) with 29 patients on each arm initiating treatment. A similar proportion of patients did not complete treatment and follow-up on the D-met arm (8/29: $28 \%)$ as compared to the placebo arm (5/29: 17\%) 
Phase 2 Study of D-Methionine to Prevent Mucositis

$(\mathrm{p}=0.6)$. On the experimental arm $4 / 8$ patients not completing treatment were for adverse events all 4 of which were from nausea and/or vomiting. There was one case of grade 1 , two of grade 2, and one of grade 3. On the control arm one patient had neutropenic fever and sepsis and subsequently died on day 32 of study. This was not felt to be related to study drug (placebo).

Adverse events by maximum intensity for those reported in $>10 \%$ of all patients are listed in Table 3. All patients experienced at least one adverse event of grade 1 or greater. The proportion of patient experiencing Grade 2+ AEs (27/29: 93\% control vs. 28/29: 97\% Dmet, $\mathrm{p}=0.7)$ or Grade 3+ AEs (12/29:41\% control vs. 10/29:34\% D-met, $\mathrm{p}=0.8)$ were also not different between treatment arms There was greater nausea with D-met as compared to placebo $(55 \%$ vs. $17 \%, \mathrm{p}=0.005)$ but the majority $(11 / 16)$ was Grade 1 . There was no difference in Grade 2+ nausea between arms $(17 \%$ vs. 10\%, $\mathrm{p}=0.7)$. For grade 2 or greater AEs only pain in oral cavity (Grade 2+: 23/29 (79\%) placebo vs. 13/29 (45\%) Dmet, $p=0.0165$ ) and body odor (Grade 2+: $1 / 29$ (3\%) placebo vs. 12/29 (41\%) D-met, $\mathrm{p}=0.0015$ ) were different between arms. There were no differences in adverse laboratory assessments (Supplemental Tables 5 and 6).

Serious adverse events per protocol are provided (Supplemental Table 7) with all SAEs deemed not related to study medication and no differences in the rate of SAEs per arm (Placebo:13, D-met:11, $\mathrm{p}>0.5$ ). There were also no differences in significant protocol violations between arms (Supplemental Table 8). One notable violation is that 11/29 (38\%) of D-met and 12/29 (41\%) of placebo patients received 5-floururacil in addition to cisplatin during ChemoRT which was not part of the protocol treatment.

\section{Mucositis Evaluations}

Patients were evaluated by the treating team at the start of treatment, weekly during RT, and then post treatment day 30 (see Figure 1). Three mucositis scales were evaluated: the WHO physicians scored scale (Figure 2A), the RTOG Gross Physician Rating (Figure 2B), and the RTOG Functional Patient Rating (Figure 2C). A composite scale was also utilized that was the highest score on each of the three scales (Figure 2D). For both 
physician scored scales (WHO and RTOG) there was a greater rate of mucositis (on a 0-4 scale) with placebo as compared to D-met ( $\mathrm{p}=0.007 \mathrm{WHO}, \mathrm{p}=0.0009$ RTOG) as well as a higher rate of Grade 3-4 mucositis (41\% vs. 17\% WHO, $\mathrm{p}=0.045 ; 48 \%$ vs. $21 \% \mathrm{RTOG}$, $\mathrm{p}=0.0285$ ). For the RTOG Functional Patient Rating there was a lower rate of mucositis overall with $\mathrm{D}$-met $(\mathrm{p}=0.0023)$ but the difference in grade 3-4 mucositis favoring $\mathrm{D}-\mathrm{met}$ was not statistically significant $(41 \%$ vs. $24 \%, \mathrm{p}=0.16)$.

The primary end-point, pre-determined prior to analysis, was a reduction in the rate of grade 3-4 mucositis using the composite scale (Figure 2D). This was twice as likely with placebo (14/29: 48\%) as compared to D-met (7/29: 24\%), but this difference was not statistically significant $(\mathrm{p}=0.058)$. However, the overall mucositis score $(0-4)$ was lower with the use of $\mathrm{D}$-met ( $\mathrm{p}=0.0018)$. On the composite scale $31 \%(9 / 29)$ of D-met patients had grade $0-1$ mucositis while this was only $3 \%(1 / 29)$ on the placebo arm $(p=0.008)$. In addition, if grade 3 and 4 mucositis were considered separately (where there were 2 cases (7\%) grade 4 on the control arm as compared to zero cases on the experimental arm) there was also a difference favoring D-met $(p=0.033)$. Finally one patient on the placebo arm died of sepsis after developing grade 4 mucositis (by the WHO and the RTOG patient scale with grade 3 mucositis by the RTOG physician scale) after 38 Gy in 2 Gy fractions and 4 weekly doses of cisplatin while there were no deaths on the experimental arm.

For those who developed grade 3-4 mucositis using the composite scale (14 placebo and 7 control) this occurred on average 24 (SD:13) days from starting treatment on the placebo arm and $30(\mathrm{SD}: 8)$ days on the D-met arm $(\mathrm{p}>0.2)$.

\section{Secondary End-Points}

\section{Planned Secondary End-Points}

An additional scoring system was also utilized per protocol where 9 areas in the mouth were assessed weekly for both ulceration and erythema (See Supplemental Table 4)(38). The instrument was scored as described with the data plotted in Figure 3A as the average peak scores summated from each of those 9 areas over time. For ulceration as a 
Phase 2 Study of D-Methionine to Prevent Mucositis

continuous scale (0-3) the use of D-met was associated with a 0.7 point reduction in the average peak ulceration score (Difference: -0.70 (StdError:0.24), $\mathrm{p}=0.006$ ) which was 2.2 (0.68) for Placebo and 1.5 (1.1) for D-met. While for erythema on a continuous scale (02) the use of D-met was associated with a 0.5 point reduction in peak erythema score (Difference: -0.52 (StdError:0.18), p=0.005) which was $1.6(0.49)$ for Placebo and 1.1 (0.82) for D-met.

No significant differences were found for any of the other planned secondary end-points. There was no difference in hospitalization rates (3/29 (10\%) Placebo vs. 2/29 (7\%) Dmet, $\mathrm{p}=0.64)$ nor weight loss (4.4 kg (SD:3.0) Placebo vs. 4.2 (SD:3.2) D-met, $\mathrm{p}=0.8)$. Supportive therapy use was also not different for either opioid analgesics for pain control (12/29 (41\%) placebo vs. $9 / 29$ (31\%) D-met, $\mathrm{p}=0.62)$ or the need for total parenteral nutrition $(4 / 29(14 \%)$ placebo vs. $1 / 29(3 \%)$ for $\mathrm{D}-\mathrm{met}, \mathrm{p}=0.16)$.

Per protocol the last day of follow-up was scheduled for 30 days after the completion of RT with no difference in attendance at this time (24/29 (83\%) placebo vs. 21/29 (72\%) Dmet, $\mathrm{p}=0.35)$. Treatment response was assessed by CT scan with $50 \%$ of subjects $(29 / 58$; Placebo=16, D-met=13) having a baseline CT scan, measurable disease on this scan, and a follow-up scan at day 30 (Supplemental Table 9). Based upon radiographic review blinded to treatment allocation there was no difference in response rates between treatments with 62.5\% (10/16) response (PR or CR) for placebo and 46.2\% response $(6 / 13)$ for D-met $(p=0.48)$.

\section{Unplanned Secondary Analyses}

\section{Peak and Area Under the Time / Mucositis Curve}

As an additional unplanned analysis the time-dependent nature of mucositis was plotted for the patient reported RTOG scale in Figure 3B. Mucositis on a scale of 0-4 is plotted from the baseline visit $(0)$ through the weekly treatment visits (1-7) and the final followup appointment (8). The integral of mucositis over time was calculated and reported as the Area Under the Curve (AUC) which was higher for Placebo (AUC: 8.3 (95\%CI:7.6- 
8.9)) as compared to D-met (AUC: 6.3 (95\%CI:5.6-7.0), $\mathrm{p}=0.036)$. This led to a protective factor (Placebo/D-met) of 1.3.

For Peak mucositis there was a similar relationship with average peak value of 1.9 (95\%CI:1.5-2.4) for Placebo as compared to 1.3 (95\%CI:1.1-1.6) for D-met which was statistically different $(\mathrm{p}=0.005)$ with a protective factor of 1.5. Peak mucositis was statistically different at weeks 4 and 5 but not at other time-points. A similar relationship for time-dependent mucositis and peak mucositis with similar protective factors was seen for all 3 scales (Supplemental Table 10).

\section{Missing Data}

One potential confounding factor is that more patients withdrew from treatment with Dmet than with placebo. For those who dropped out the mucositis score on their last assessment was compared between those with Placebo or D-met for any patient who had less than 9 mucositis evaluations (Supplemental Table 11). This revealed that patients who missed evaluations on the Placebo arm had higher mucositis scores prior to missing data than those on the D-met arm (2.8-3.0 vs. 1.0-1.2, all p-values $<0.002)$. In addition, patients non-evaluable on the Placebo arm had higher peak mucositis scores than Placebo patients who completed treatment (2.8-3.0 vs. 2.0-2.0, for all 3-scales, all p-values $<0.01$ ). In contrast, those who were not evaluable on the D-met arm did not have higher peak mucositis scores then the population that was fully evaluable and treated with D-met (1.0-1.2 vs. 1.3-1.4, all p-value >0.05). However, on the D-met arm there was a trend to those missing mucositis evaluations having higher rates of grade $1+$ nausea $(42 \% \mathrm{vs}$. $18 \%, \mathrm{p}=0.09$ ) without a difference in grade 2 or greater nausea; while on the placebo arm there was no difference in grade 1 or greater than grade 1 nausea for those who completed all mucositis evaluation as compared to those who missed mucositis assessments $(\mathrm{p}>0.5)$. Nevertheless, differences in timing of these mucositis evaluations in those who dropped out of therapy or did not limit the conclusions to be made based upon an uplanned secondary analysis. 
Phase 2 Study of D-Methionine to Prevent Mucositis

\section{Radiation Dose and Mucositis}

We also evaluated the impact of RT dose on mucositis for the WHO scale (Supplemental Table 12). By univariate regression increasing radiation dose $(<20,20-39,40-59,60-70$ Gy) correlated with increasing mucositis $(p=0.03)$ while D-met was protective $(p=0.0005)$. On multivariate regression the use of $D$-met retained significance $(p=0.001)$ while radiation dose was borderline $(\mathrm{p}=0.064)$. When analyzed as the likelihood of having Grade 3-4 mucositis by logistic regression the use of D-met after adjusting for RT dose was associated with a substantial reduction in the rate of Grade 3-4 mucositis (Odds Ratio: 0.29 (95\%CI:0.09-0.99), $\mathrm{p}=0.05)$ while RT dose was not correlated with Grade 3-4 mucositis $(\mathrm{p}=0.93)$.

\section{The Use of 5-Flourouracil and Mucositis}

Some patients also received 5-FU (12 in the Placebo group and 11 in the D-met group, Supplemental Table 13) which was outside of recommended protocol therapy. Logistic regression was performed to assess the rate of Grade 3-4 mucositis as a function of treatment (Placebo vs. D-met) as well as the use of 5-FU (No vs. Yes) for the WHO scale. Overall in this model the use of D-met was protective of Grade 3-4 mucositis (Odds Ratio: 0.29 (95\%CI:0.09-0.98), $\mathrm{p}=0.047)$ while the use of 5-FU did not influence mucositis (OR: 0.72 (95\%CI:0.21-2.4), p=0.60). Similarly, when analyzing the complete WHO scale for mucositis (0-4) the use of D-met was associated with an approximately 1.0 point decrease in maximal mucositis score (Difference : 0.87 (StDev: 0.23), $\mathrm{p}=0.0005$ ) while 5-FU use did not influence score (Difference: 0.06 (StDev:0.24), $\mathrm{p}=0.81)$.

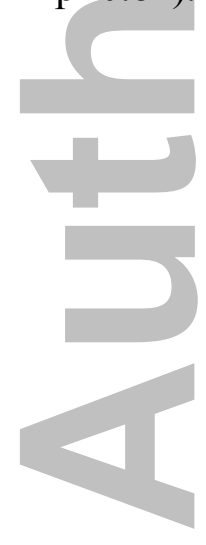


Phase 2 Study of D-Methionine to Prevent Mucositis

\section{Discussion}

This multi-institutional phase 2 trial was undertaken to assess if the efficacy observed in the single center Phase I trial of oral D-methionine to prevent OM could be confirmed. In planning the trial the control arm was assumed to have a 70\% incidence of grade 3-4 mucositis and that following D-met it would be $10 \%$. As such a sample size of 40 evaluable patients was needed. The observed rate of grade 3-4 mucositis was lower on the control arm than anticipated with 14/29 patients (48\%) having severe mucositis while that in the experimental arm was higher than anticipated with 7/29 (24\%) having severe mucositis. As a result this study did not meet its primary end-point of comparing the rate of grade 3-4 mucositis between arms based upon the composite scale $(p=0.058)$. Based upon other studies it appears that the primary deficiency was that the $70 \%$ assumed rate of grade 3-4 mucositis on the control arm (as reported for the phase I trial (37)) was higher than observed on the control arm of the current study; although the rate we did observe is more in line with other published clinical trials. As a result statistical significance was not obtained for the primary end-point.

Of note a number of planned and unplanned complementary analyses of mucositis were also undertaken with strong support for reduced mucositis in patients treated with D-met. This included decreased mucositis when looking at all 4 scales utilized over their full range (WHO, RTOG physician, RTOG functional patient, and the composite scale, all $\mathrm{p}<0.003$ ). In addition, no grade 4 mucositis was noted in any D-met treated patients, while $2 / 29(7 \%)$ of patients had grade 4 mucositis when treated with placebo, and one patient died secondary to sepsis on the placebo arm (potentially related to grade 4 mucositis). If grade 4 mucositis is addressed separately from grade 3 then all 4 scales would also support a protective effect of D-met (all p<0.009). Another pre-planned analysis was the use of the OSSFSA to assess ulceration and erythema separately across 9 areas of the oral cavity or oropharynx where D-met resulted in lower scores for both of these planned evaluations (both $\mathrm{p}<0.007$ ). It is well documented that treatment delays for SCCHN decrease local control and in a pre-planned analysis the use of D-met was associated with an approximate 6 day shorter treatment course than placebo $(p=0.05)$; while patients missing treatment on the placebo arm had higher mucositis scores then 
Phase 2 Study of D-Methionine to Prevent Mucositis

patients remaining on treatment consistent with treatment breaks for mucositis in the placebo arm (all $\mathrm{p}<0.0016)$. Finally, unplanned analyses taking into account the time depended exposure of mucositis as the AUC as well as the impact of both RT dose and the use of 5-FU concurrent with cisplatin and RT all supported a protective effect of Dmet (all $\mathrm{p}<0.05)$.

In the preclinical data a stronger correlation was noted between the $\mathrm{C}_{\max }$ of Dmet and radiation protection factor $\left(\mathrm{R}^{2}=0.94\right)$ as compared to $\mathrm{D}$-met AUC $\left(\mathrm{R}^{2}=0.31\right)$ (D.A.H. unpublished data). Peak serum concentrations were higher in humans (100 mg/kg po, $\left.\mathrm{C}_{\max }=192 \mu \mathrm{g} / \mathrm{mL}\right)(37)$ as compared to rodents $\left(150 \mathrm{mg} / \mathrm{kg}\right.$ po, $\left.\mathrm{C}_{\max }=71 \mu \mathrm{g} / \mathrm{mL}\right)(34)$ while given the longer half-life in humans $(3.0 \mathrm{hrs} v s .1 .0 \mathrm{hrs})$ the total exposure following oral dosing was even higher in man (AUC $793 v s .211 \mu \mathrm{g} * \mathrm{hr} / \mathrm{mL}$ ). $(34,37$ ) The PF observed here of 1.3-1.5 is lower than that predicted based upon extrapolating from a comparable $\mathrm{C}_{\max }$ in rodents which would have been 2.1.(34) Nevertheless, given the much longer half-life in man (and correspondingly much higher AUC) this is still most consistent with radiation protection correlating best with peak serum concentration. Notably in rodents peak serum concentrations were markedly higher after IV administration then after PO which could potentially have implications for further development of D-met as a radioprotector.

There were no SAE's noted with the use of D-met although 4 patients did withdraw from the study due to nausea/vomiting (most grade 1-2). This is consistent with previous reports of pharmacologic doses of methionine. As a result it is recommended that antiemetics that are active in the setting of mildly emesis inducing drugs be utilized prophylactically if D-met is going to be administered as outlined herein.

Oral mucositis continues to be a significant burden for patients treated for SCCHN with combined chemoRT. The current study was undertaken in India where consumption of betel nut leads to a high rate of squamous cell cancers involving the oral cavity and oropharynx. However, in western countries alcohol and tobacco related SCCHN were traditionally more prevalent while more recently there has been a significant increase in 
SCCHN related to human papilloma virus infection. Nevertheless, the combination of radiotherapy and chemotherapy is still associated with oral or pharyngeal mucositis in a high proportion of patients regardless of patient heritage or the causative agent for their SCCHN (2). In addition, the treatment utilized here with CT planned 2- or 3D conformal therapy also does not reflect current treatment standards; however, newer technologies such as parotid sparing intensity modulated RT (IMRT) have not reduced mucositis, perhaps due to spreading dose more to mucosal surfaces with IMRT. The only phase III trial comparing 3D-conformal RT to parotid sparing IMRT reported a numerically higher but not significantly different rate of grade 3-4 mucositis in those getting IMRT as compared to 3D-treatments $(60 \%$ IMRT vs. $44 \% 3 \mathrm{D}, \mathrm{p}>0.05)(39)$. Similarly in a randomized trial the use of every 3-week cisplatin $\left(100 \mathrm{mg} / \mathrm{m}^{2}\right)$ also correlated with a higher (albeit not statistically different) rate of oral mucositis when compared to weekly cisplatin $\left(30 \mathrm{mg} / \mathrm{m}^{2}\right)(53 \%$ vs. $40 \%, \mathrm{p}>0.05)(40)$. In this context the rate of grade $3-4$ mucositis observed here using conventional RT and weekly cisplatin (48\%) is consistent with these previous reports while that with the addition of D-met $(24 \%)$ is lower. As a result the protective effect of D-met potentially identified herein likely is still applicable even with different demographic and treatment related characteristics.

ron

A number of other agents have been reported recently as to their ability to mitigate oral mucositis. Most prominently is topical honey where 4 small phase 3 trials (all performed ex-US) appeared to show significantly reduced mucositis as compared to placebo or best standard of care with the most common regimen being topical honey administered before and two times after RT for up to 6 hours. Given the antibacterial and anti-microbial properties reported for honey it is felt that this may be its mechanism of action. A recent large phase 2 trial performed by the RTOG in patients receiving thoracic RT, however, did not note a benefit of Manuka Honey using either liquid or lozenge formulation as compared to best standard of care in reducing esophagitis(41). Benzydamine (a locally acting topical non-steroidal anti-inflammatory) was also demonstrated to decrease $\mathrm{OM}$ when compared to saline mouth wash daily during RT with the greatest effect in reducing oral pain(42). Caphasol, which is marketed to lubricate the mouth for xerostomia, did not result in any decrease in mucositis when provided during RT(43). Finally, in a single 
Phase 2 Study of D-Methionine to Prevent Mucositis

dose study the use of Doxepin (a tri-cyclic anti-depressant) or "Magic Mouth Wash" (lidocaine containing rinse) each compared to placebo noted decrease oral pain in the first 60 minutes with either experimental agent while those receiving doxepin had increased fatigue compared to placebo(44).

Taken together the results reported here are suggestive of a protective effect of Dmethionine in preventing OM. Although the study did not achieve its primary end-point the remainder of the data are robust and supportive of an effect. Further studies of D-met powered to assess tumor response as well as mucosal protection are warranted.
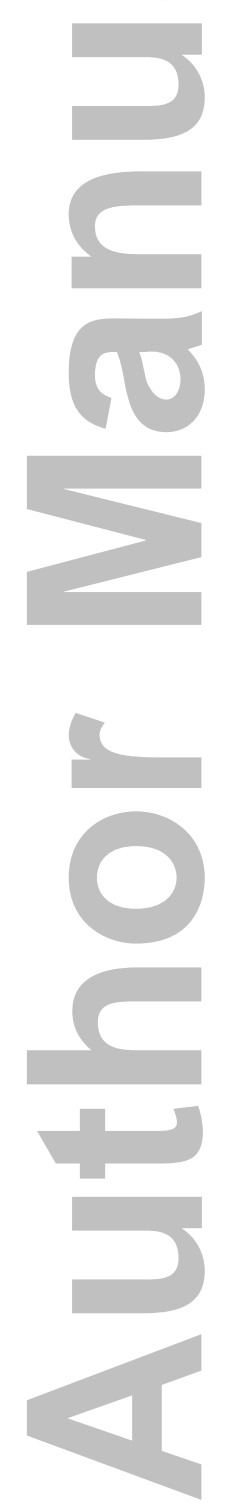
Phase 2 Study of D-Methionine to Prevent Mucositis

\section{Figure Legends}

\section{Figure 1 : Consort Diagram}

Figure 2: Maximum Mucositis score (and standard error) observed for the World Health Organization (WHO) (A), Radiation Therapy Oncology Group (RTOG) Physician (B), RTOG Functional Patient (C), or Composite Scale (D)

Figure 3: Oral mucositis by maximum grade using the Objective Scoring System for Site Assessment (mean number of observations with standard error) by treatment arm for placebo or D-methionine (D-met) treatment. (A). Time dependent analysis of mucositis using the RTOG Functional Patient Rating (mean score with standard error) along with calculated peak and area under the curve (AUC) (B) 
Phase 2 Study of D-Methionine to Prevent Mucositis

References Cited:

1. Siegel RL, Miller KD, Jemal A. Cancer Statistics, 2017. CA Cancer J Clin 2017;67(1):7-30 doi 10.3322/caac.21387.

2. Moslemi D, Nokhandani AM, Otaghsaraei MT, Moghadamnia Y, Kazemi S, Moghadamnia AA. Management of chemo/radiation-induced oral mucositis in patients with head and neck cancer: A review of the current literature. Radiother Oncol 2016;120(1):13-20 doi 10.1016/j.radonc.2016.04.001.

3. Allison RR, Vongtama V, Vaughan J, Shin KH. Symptomatic acute mucositis can be minimized or prophylaxed by the combination of sucralfate and fluconazole. Cancer Invest 1995;13(1):16-22.

4. Foote RL, Loprinzi CL, Frank AR, O'Fallon JR, Gulavita S, Tewfik HH, et al. Randomized trial of a chlorhexidine mouthwash for alleviation of radiationinduced mucositis. J Clin Oncol 1994;12(12):2630-3 doi 10.1200/JCO.1994.12.12.2630.

5. Gordon B, Spadinger A, Hodges E, Ruby E, Stanley R, Coccia P. Effect of granulocyte-macrophage colony-stimulating factor on oral mucositis after hematopoietic stem-cell transplantation. J Clin Oncol 1994;12(9):1917-22 doi 10.1200/JCO.1994.12.9.1917.

6. Crawford H, Claspy J, Vincent M, Tomita D, Mazunet R. Effect of figrastim (rmetHug-CSF) on oral mucositis in patients with small cell lung cancer (SCLC) receiving chemotherapy (cyclophosphamide, doxorubicin, and etoposide (CAE)). 1994. p A1523.

7. Chi KH, Chen $\mathrm{CH}$, Chan WK, Chow KC, Chen SY, Yen SH, et al. Effect of granulocyte-macrophage colony-stimulating factor on oral mucositis in head and neck cancer patients after cisplatin, fluorouracil, and leucovorin chemotherapy. J Clin Oncol 1995;13(10):2620-8.

8. Cartee L, Petros WP, Rosner GL, Gilbert C, Moore S, Affronti ML, et al. Evaluation of GM-CSF mouthwash for prevention of chemotherapy-induced mucositis: a randomized, double-blind, dose-ranging study. Cytokine 1995; 7(5):471-7.

9. Spielberger R, Stiff P, Bensinger W, Gentile T, Weisdorf D, Kewalramani T, et al. Palifermin for oral mucositis after intensive therapy for hematologic cancers. The New England journal of medicine 2004;351(25):2590-8.

10. Verdi CJ, Garewal HS, Koenig LM, Vaughn B, Burkhead T. A double-blind, randomized, placebo-controlled, crossover trial of pentoxifylline for the prevention of chemotherapy-induced oral mucositis. Oral surgery, oral medicine, oral pathology, oral radiology, and endodontics 1995;80(1):36-42.

11. Osaki T, Ueta E, Yoneda K, Hirota J, Yamamoto T. Prophylaxis of oral mucositis associated with chemoradiotherapy for oral carcinoma by Azelastine hydrochloride (Azelastine) with other antioxidants. Head \& neck 1994;16(4):3319.

12. Labar B, Mrsic M, Pavletic Z, Bogdanic V, Nemet D, Aurer I, et al. Prostaglandin E2 for prophylaxis of oral mucositis following BMT. Bone marrow transplantation 1993;11(5):379-82. 
13. Shenep JL, Kalwinsky DK, Hutson PR, George SL, Dodge RK, Blankenship KR, et al. Efficacy of oral sucralfate suspension in prevention and treatment of chemotherapy-induced mucositis. The Journal of pediatrics 1988;113(4):758-63.

14. Biswal BM, Zakaria A, Ahmad NM. Topical application of honey in the management of radiation mucositis: a preliminary study. Support Care Cancer 2003;11(4):242-8 doi 10.1007/s00520-003-0443-y.

15. Khanal B, Baliga M, Uppal N. Effect of topical honey on limitation of radiationinduced oral mucositis: an intervention study. Int J Oral Maxillofac Surg 2010;39(12):1181-5 doi 10.1016/j.ijom.2010.05.014.

16. Motallebnejad M, Akram S, Moghadamnia A, Moulana Z, Omidi S. The effect of topical application of pure honey on radiation-induced mucositis: a randomized clinical trial. J Contemp Dent Pract 2008;9(3):40-7.

17. Rashad UM, Al-Gezawy SM, El-Gezawy E, Azzaz AN. Honey as topical prophylaxis against radiochemotherapy-induced mucositis in head and neck cancer. J Laryngol Otol 2009;123(2):223-8 doi 10.1017/S0022215108002478.

18. Jebb SA, Osborne RJ, Maughan TS, Mohideen N, Mack P, Mort D, et al. 5fluorouracil and folinic acid-induced mucositis: no effect of oral glutamine supplementation. British journal of cancer 1994;70(4):732-5.

19. Rocke LK, Loprinzi CL, Lee JK, Kunselman SJ, Iverson RK, Finck G, et al. A randomized clinical trial of two different durations of oral cryotherapy for prevention of 5-fluorouracil-related stomatitis. Cancer 1993;72(7):2234-8.

20. Cowen D, Tardieu C, Schubert M, Peterson D, Resbeut M, Faucher C, et al. Low energy Helium-Neon laser in the prevention of oral mucositis in patients undergoing bone marrow transplant: results of a double blind randomized trial.

International journal of radiation oncology, biology, physics 1997;38(4):697-703.

21. Bossi P, Bergamini C, Miceli R, Cova A, Orlandi E, Resteghini C, et al. Salivary Cytokine Levels and Oral Mucositis in Head and Neck Cancer Patients Treated With Chemotherapy and Radiation Therapy. Int J Radiat Oncol Biol Phys 2016;96(5):959-66 doi 10.1016/j.ijrobp.2016.08.047.

22. Zhu XX, Yang XJ, Chao YL, Zheng HM, Sheng HF, Liu HY, et al. The potential effect of oral microbiota in the prediction of mucositis during radiotherapy for $\begin{array}{llll}\text { nasopharyngeal carcinoma. } & \text { EBioMedicine } & \mathbf{2 0 1 7} & \text { doi }\end{array}$ 10.1016/j.ebiom.2017.02.002.

23. Benevenga NJ. Toxicities of methionine and other amino acids. Journal of agricultural and food chemistry 1974;22(1):2-9.

24. Walser M, Lund P, Ruderman NB, Coulter AW. Synthesis of essential amino acids from their alpha-keto analogues by perfused rat liver and muscle. The Journal of clinical investigation 1973;52(11):2865-77.

25. Stekol JA, Szaran J. Pathological effects of excessive methionine in the diet of growing rats. The Journal of nutrition 1962;77:81-90.

26. Friedman M. Chemistry, nutrition, and microbiology of D-amino acids. Journal of agricultural and food chemistry 1999;47(9):3457-79.

27. Crome P, Vale JA, Volans GN, Widdop B, Goulding R. Oral methionine in the treatment of severe paracetamol (Acetaminophen) overdose. Lancet 1976;2(7990):829-30. 
Phase 2 Study of D-Methionine to Prevent Mucositis

28. Crome P, Vale JA, Volans GN, Widdop B, Goulding R. Methionine in treatment of acetaminophen poisoning. The New England journal of medicine 1977;296(14):824.

29. Crome P, Volans GN, Vale JA, Widdop B, Goulding R. The use of methionine for acute paracetamol poisoning. The Journal of international medical research 1976;4(4 Suppl):105-11.

30. Monteagudo FS, Straughan JL, van der Merwe LP. The choice between intravenous $\mathrm{N}$-acetylcysteine and oral methionine in paracetamol poisoning. South African medical journal $=$ Suid-Afrikaanse tydskrif vir geneeskunde 1986;69(5):279.

31. Vale JA, Meredith TJ, Goulding R. Treatment of acetaminophen poisoning. The use of oral methionine. Archives of internal medicine 1981;141(3 Spec No):3946.

32. Campbell KC, Rybak LP, Meech RP, Hughes L. D-methionine provides excellent protection from cisplatin ototoxicity in the rat. Hear Res 1996;102(1-2):90-8.

33. Reser D, Rho M, Dewan D, Herbst L, Li G, Stupak H, et al. L- and D- methionine provide equivalent long term protection against CDDP-induced ototoxicity in vivo, with partial in vitro and in vivo retention of antineoplastic activity. Neurotoxicology 1999;20(5):731-48.

34. Vuyyuri SB, Hamstra DA, Khanna D, Hamilton CA, Markwart SM, Campbell $\mathrm{KC}$, et al. Evaluation of D-methionine as a novel oral radiation protector for prevention of mucositis. Clin Cancer Res 2008;14(7):2161-70.

35. Cotrim AP, Yoshikawa M, Sunshine AN, Zheng C, Sowers AL, Thetford AD, et al. Pharmacological protection from radiation $+/$ - cisplatin-induced oral mucositis. Int J Radiat Oncol Biol Phys 2012;83(4):1284-90 doi 10.1016/j.ijrobp.2011.09.026.

36. Roscioli N, Kari G, Booty JO, Rehemtulla A, Rodeck U, Dicker AP. 2643. International Journal of Radiation Oncology • Biology • Physics;66(3):S568 doi 10.1016/j.ijrobp.2006.07.1057.

37. Hamstra DA, Eisbruch A, Naidu MU, Ramana GV, Sunkara P, Campbell KC, et al. Pharmacokinetic analysis and phase 1 study of MRX-1024 in patients treated with radiation therapy with or without cisplatinum for head and neck cancer. Clin Cancer Res 2010;16(9):2666-76 doi 10.1158/1078-0432.CCR-09-3318.

38. Sonis ST, Eilers JP, Epstein JB, LeVeque FG, Liggett WH, Jr., Mulagha MT, et al. Validation of a new scoring system for the assessment of clinical trial research of oral mucositis induced by radiation or chemotherapy. Mucositis Study Group. Cancer 1999;85(10):2103-13.

39. Nutting CM, Morden JP, Harrington KJ, Urbano TG, Bhide SA, Clark C, et al. Parotid-sparing intensity modulated versus conventional radiotherapy in head and neck cancer (PARSPORT): a phase 3 multicentre randomised controlled trial. Lancet Oncol 2011;12(2):127-36 doi 10.1016/S1470-2045(10)70290-4.

40. Sahoo TK, Samanta DR, Senapati SN, Parida K. A Comparative Study on Weekly Versus Three Weekly Cisplatinum Based Chemoradiation in Locally Advanced Head and Neck Cancers. J Clin Diagn Res 2017;11(1):XC07-XC11 doi 10.7860/JCDR/2017/24765.9293. 
41. Fogh SE, Deshmukh S, Berk LB, Dueck AC, Roof K, Yacoub S, et al. A Randomized Phase 2 Trial of Prophylactic Manuka Honey for the Reduction of Chemoradiation Therapy-Induced Esophagitis During the Treatment of Lung Cancer: Results of NRG Oncology RTOG 1012. Int J Radiat Oncol Biol Phys 2017;97(4):786-96 doi 10.1016/j.ijrobp.2016.11.022.

42. Rastogi M, Khurana R, Revannasiddaiah S, Jaiswal I, Nanda SS, Gupta P, et al. Role of benzydamine hydrochloride in the prevention of oral mucositis in head and neck cancer patients treated with radiotherapy (>50 Gy) with or without chemotherapy. Support Care Cancer 2017;25(5):1439-43 doi 10.1007/s00520016-3548-9.

43. Wong KH, Kuciejewska A, Sharabiani MT, Ng-Cheng-Hin B, Hoy S, Hurley T, et al. A randomised controlled trial of Caphosol mouthwash in management of radiation-induced mucositis in head and neck cancer. Radiother Oncol 2017;122(2):207-11 doi 10.1016/j.radonc.2016.06.015.

44. Miller RC, Le-Rademacher J, Sio TTW, Leenstra JL, Rine GP, Curtis A, et al. A Phase III, Randomized Double-Blind Study of Doxepin Rinse versus Magic Mouthwash versus Placebo in the Treatment of Acute Oral Mucositis Pain in Patients Receiving Head and Neck Radiotherapy with or without Chemotherapy (Alliance A221304). International Journal of Radiation Oncology • Biology • Physics;96(5):938 doi 10.1016/j.ijrobp.2016.09.047. 


\begin{tabular}{|c|c|c|c|}
\hline & $\begin{array}{l}\text { D-methionine } \\
(\text { number }=29)\end{array}$ & $\begin{array}{c}\text { Placebo } \\
(\text { number }=29)\end{array}$ & p-value \\
\hline $\begin{array}{l}\text { Age: (years) } \\
\text { Mean (SD) } \\
\text { Median (Min, Max) }\end{array}$ & $\begin{array}{l}50.2(11.4) \\
52(23,64)\end{array}$ & $\begin{array}{c}47.7(9.4) \\
50(28,64)\end{array}$ & $0.4^{\mathrm{b}}$ \\
\hline $\begin{array}{l}\text { Gender: [Number(\%)] } \\
\text { Male } \\
\text { Female }\end{array}$ & $\begin{array}{l}22(75.9) \\
7(24.1)\end{array}$ & $\begin{array}{l}22(75.9) \\
7(24.1)\end{array}$ & $1.0^{\mathrm{c}}$ \\
\hline $\begin{array}{l}\text { Ethnicity: [Number(\%)] } \\
\text { Indian }\end{array}$ & $29(100)$ & $29(100)$ & $1.0^{\mathrm{c}}$ \\
\hline $\begin{array}{l}\text { Weight: }(\mathrm{Kg}) \\
\text { Mean (SD) } \\
\text { Median (Min, Max) }\end{array}$ & $\begin{array}{l}56.3(10.4) \\
56(35,80)\end{array}$ & $\begin{array}{l}53.3(11.0) \\
49(30,73)\end{array}$ & $0.3^{\mathrm{b}}$ \\
\hline $\begin{array}{l}\text { Body Mass Index: }\left(\mathrm{kg} / \mathrm{m}^{2}\right) \\
\text { Mean (SD) } \\
\text { Median (Min, Max) }\end{array}$ & $\begin{array}{c}21.6(3.5) \\
22.0(15.1,30)\end{array}$ & $\begin{array}{c}20.9(4.7) \\
19.9(11.7,29.9)\end{array}$ & $0.5^{\mathrm{b}}$ \\
\hline $\begin{array}{l}\text { Karnofsky Performance Status: } \\
\text { Mean (SD) } \\
\text { Median (Min, Max) } \\
70[\text { Number }(\%)] \\
80[\text { Number }(\%)] \\
90[\text { Number }(\%)] \\
\end{array}$ & $\begin{array}{c}88.2(4.7) \\
90(70,90) \\
1(3.4) \\
3(10.3) \\
25(86.2) \\
\end{array}$ & $\begin{array}{c}87.2(4.6) \\
90(80,90) \\
0 \\
8(27.6) \\
21(72.4) \\
\end{array}$ & $0.8^{\mathrm{b}}$ \\
\hline $\begin{array}{l}\text { Time from Diagnosis to Randomization } \\
\text { Mean Days (SD) }\end{array}$ & 47.8 (92.9) & $34.5(59.9)$ & $0.5^{\mathrm{b}}$ \\
\hline $\begin{array}{l}\text { Histology/Pathology [Number(\%)] } \\
\text { Squamous Cell } \\
\text { Other (Poorly differentiated carcinoma) }\end{array}$ & $\begin{aligned} & 28(96.6) \\
& 1(3.4) \\
&\end{aligned}$ & $\begin{array}{c}27(93.1) \\
2(6.9)\end{array}$ & $1.0^{\mathrm{c}}$ \\
\hline $\begin{array}{l}\text { Site of Primary Tumor [Number }(\%)]^{\mathrm{a}} \\
\text { Oral Cavity } \\
\text { Oropharynx } \\
\text { Hypopharyngeal } \\
\text { Salivary Gland } \\
\text { Nasopharyngeal } \\
\text { Nasal Cavity and Paranasal Sinuses }\end{array}$ & $\begin{array}{c}27(93.1) \\
3(10.3) \\
1(3.4) \\
1(3.4) \\
0 \\
0\end{array}$ & $\begin{array}{c}25(86.2) \\
3(10.3) \\
1(3.4) \\
0 \\
1(3.4) \\
1(3.4)\end{array}$ & $0.7^{\mathrm{d}}$ \\
\hline $\begin{array}{l}\text { Stage [Number(\%)] } \\
\text { I } \\
\text { II } \\
\text { III } \\
\text { IV } \\
\text { Stage III/IV } \\
\text { Not Done }\end{array}$ & $\begin{array}{c}6(20.7) \\
6(20.7) \\
12(41.4) \\
4(13.8) \\
16(55.2) \\
1(3.4)\end{array}$ & $\begin{array}{c}3(10.3) \\
14(48.3) \\
7(24.1) \\
5(17.2) \\
12(41.3) \\
0\end{array}$ & $0.43^{\text {c Stage III/IV }}$ \\
\hline $\begin{array}{l}\text { Sites of Metastases [Number(\%)] } \\
\text { Any } \\
\text { Lymph nodes, neck } \\
\text { Cervical } \\
\text { Submandibular } \\
\text { Thyroid }\end{array}$ & $\begin{array}{l}6(20.7) \\
3(10.3) \\
1(3.4) \\
2(6.9) \\
1(3.4)\end{array}$ & $\begin{array}{c}3(10.3) \\
1(3.4) \\
2(6.9) \\
0 \\
0\end{array}$ & $0.5^{\mathrm{c}}$ \\
\hline
\end{tabular}

\section{Table 1 : Demographic and Clinical Characteristics}

${ }^{a}$ The total exceeds $100 \%$ because some patients had multiple sites of primary tumor and multiple sites of nodal metastases reported.

${ }^{\mathrm{b}}$ T-test

${ }^{\text {c}}$ Fisher's Exact Test

${ }^{\mathrm{d}}$ Chi-square 


\begin{tabular}{|c|c|c|c|}
\hline & $\begin{array}{l}\text { D-methionine } \\
\text { (number = 29) }\end{array}$ & $\begin{array}{c}\text { Placebo } \\
\text { (number }=29)\end{array}$ & p-value \\
\hline \multicolumn{4}{|l|}{ Radiotherapy: } \\
\hline $\begin{array}{l}\text { Number of Fractions Received per Patient } \\
\text { Mean (SD) } \\
\text { Median (Min,Max) }\end{array}$ & $\begin{array}{l}26.6(9.0) \\
30(1,35)\end{array}$ & $\begin{array}{c}29.7(5.7) \\
32(10,34)\end{array}$ & $0.4^{\mathrm{a}}$ \\
\hline $\begin{array}{l}\text { Total Gy Administered per Patient } \\
\text { Mean (SD) } \\
\text { Median(Min, Max) }\end{array}$ & $\begin{array}{l}52.2(18.6) \\
60(1.8,70)\end{array}$ & $\begin{array}{l}57.8(12.1) \\
64(18,68)\end{array}$ & $0.2^{\mathrm{a}}$ \\
\hline $\begin{array}{l}\text { Time to Complete RT per Patient [Days] } \\
\text { Mean (SD) } \\
\text { Median (Min, Max) }\end{array}$ & $\begin{array}{c}39.6(14.6) \\
42(1,65)\end{array}$ & $\begin{array}{l}47.1(12.2) \\
48(13,75)\end{array}$ & $0.05^{\mathrm{a}}$ \\
\hline $\begin{array}{l}\text { Number }(\%) \text { Treatment Device } \\
\text { Cobalt } \\
\text { Linear Accelerator }(\geq 4 \mathrm{MV}) \\
\end{array}$ & $\begin{array}{l}10(34) \\
19(66)\end{array}$ & $\begin{array}{l}10(34) \\
19(66)\end{array}$ & $1.0^{\mathrm{b}}$ \\
\hline \multicolumn{4}{|l|}{ Cisplatin: } \\
\hline $\begin{array}{l}\text { Number (\%) of Patients Receiving } \geq 1 \\
\text { Dose of Cisplatin }\end{array}$ & $25(86.2)$ & $25(86.2)$ & $1.0^{\mathrm{b}}$ \\
\hline $\begin{array}{l}\text { Number of Cisplatin Doses per Patient } \\
\text { Mean (SD) } \\
\text { Median (Min, Max) }\end{array}$ & $\begin{array}{c}3.2(1.9) \\
4(0,6)\end{array}$ & $\begin{array}{l}3.2(1.8) \\
4(0,7)\end{array}$ & $0.98^{\mathrm{a}}$ \\
\hline \multicolumn{4}{|l|}{ Study Drug: } \\
\hline $\begin{array}{l}\text { Number of Doses Administered per Patient } \\
\text { Mean (SD) } \\
\text { Median (Min, Max) }\end{array}$ & $\begin{array}{l}52.7(18.3) \\
60(2,69)\end{array}$ & $\begin{array}{l}59.5(11.5) \\
64(20,69)\end{array}$ & $0.096^{\mathrm{a}}$ \\
\hline $\begin{array}{l}\text { Number of Days Dosed per Patient } \\
\text { Mean (SD) } \\
\text { Median (Min, Max) }\end{array}$ & $\begin{array}{l}26.7(9.1) \\
30(1,35)\end{array}$ & $\begin{array}{c}29.7(5.8) \\
32(10,34) \\
\end{array}$ & $0.6^{\mathrm{a}}$ \\
\hline $\begin{array}{l}\text { Dose Drug / RT Treatment } \\
\text { Mean/Mean } \\
\text { Median/Median }\end{array}$ & $\begin{array}{l}2.0 \\
2.0\end{array}$ & $\begin{array}{l}2.0 \\
2.0\end{array}$ & $1.0^{\mathrm{b}}$ \\
\hline
\end{tabular}

$a_{\text {t-test }}$

${ }^{\mathrm{b}}$ Fisher's Exact Test 


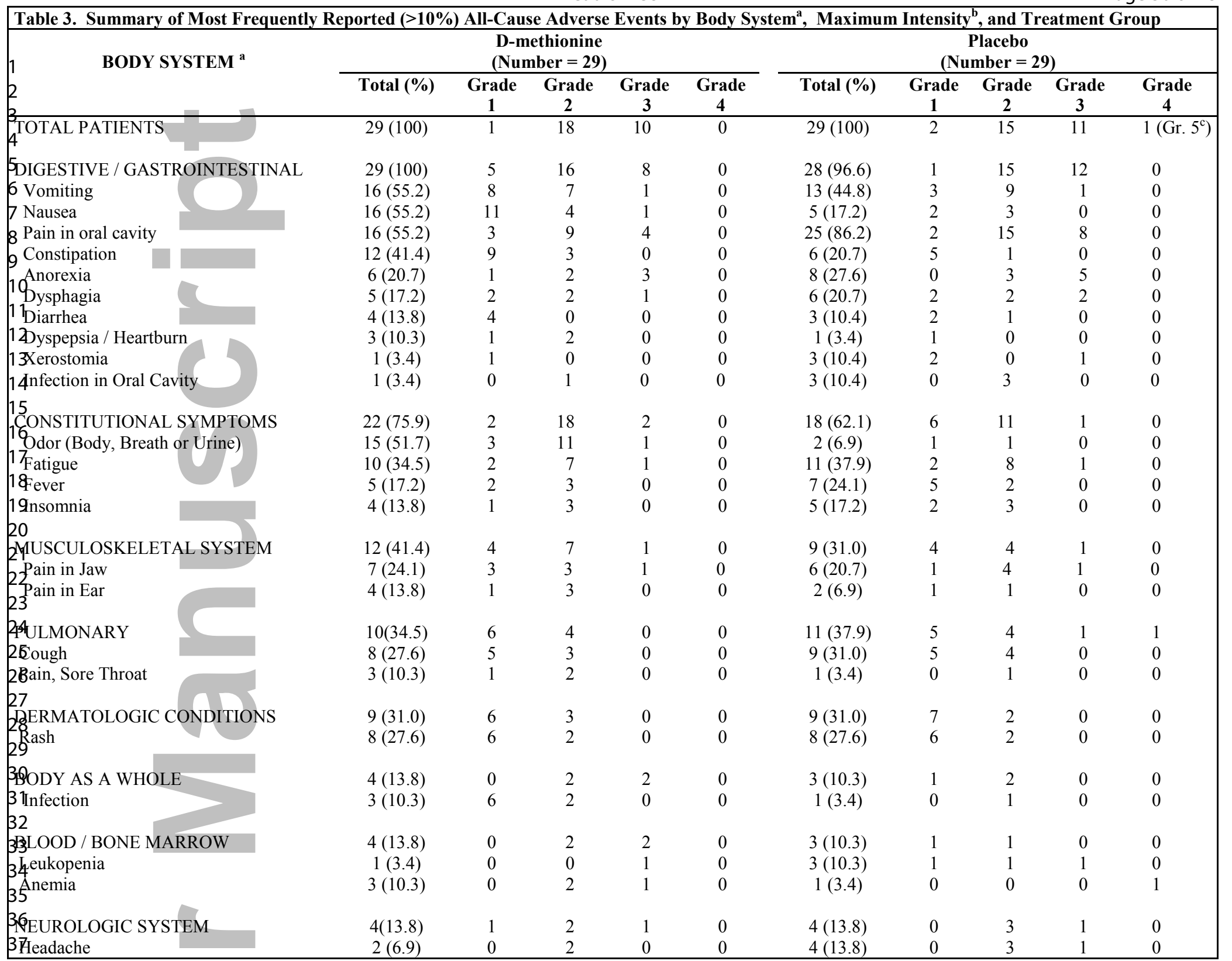

${ }^{\text {a }}$ Totals for each body system count each patient once, using the highest grade of AE reported within that body system.

${ }^{\mathrm{b}}$ Totals for individual AEs count each patient once. If multiple occurrences of the same AE were reported, the patient was counted once under the highest intensity of that event.

${ }^{\mathrm{c}}$ One patient in the placebo treatment group developed Grade 4 AEs of anemia, hypotension, and dyspnea resulting in his death (Grade 5) 


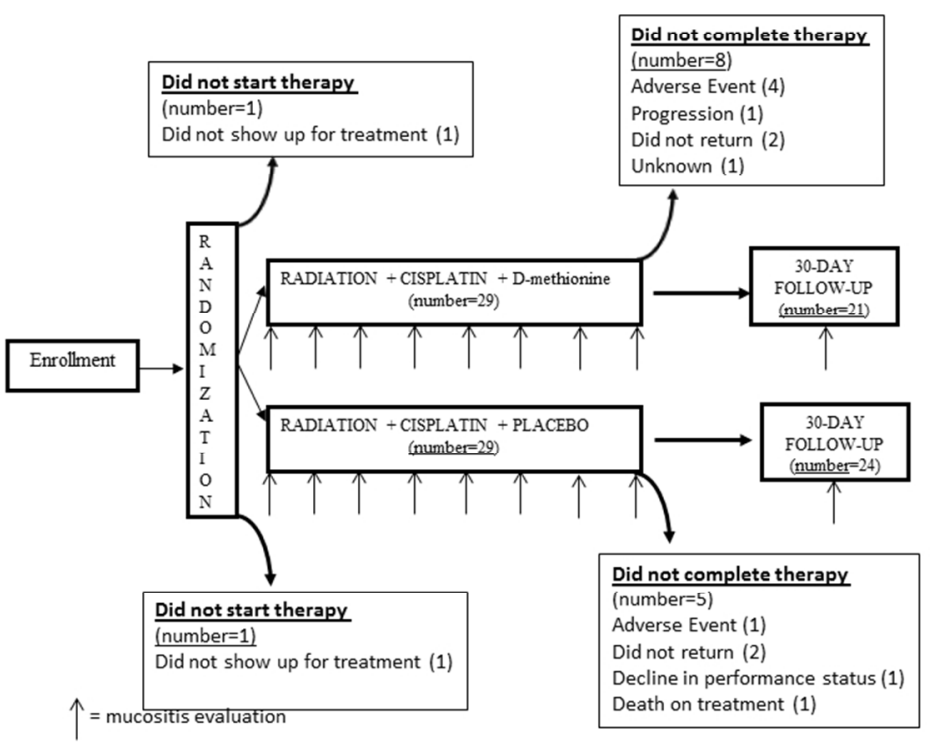

Figure 1

$254 \times 190 \mathrm{~mm}(96 \times 96$ DPI)

John Wiley \& Sons, Inc.

This article is protected by copyright. All rights reserved. 

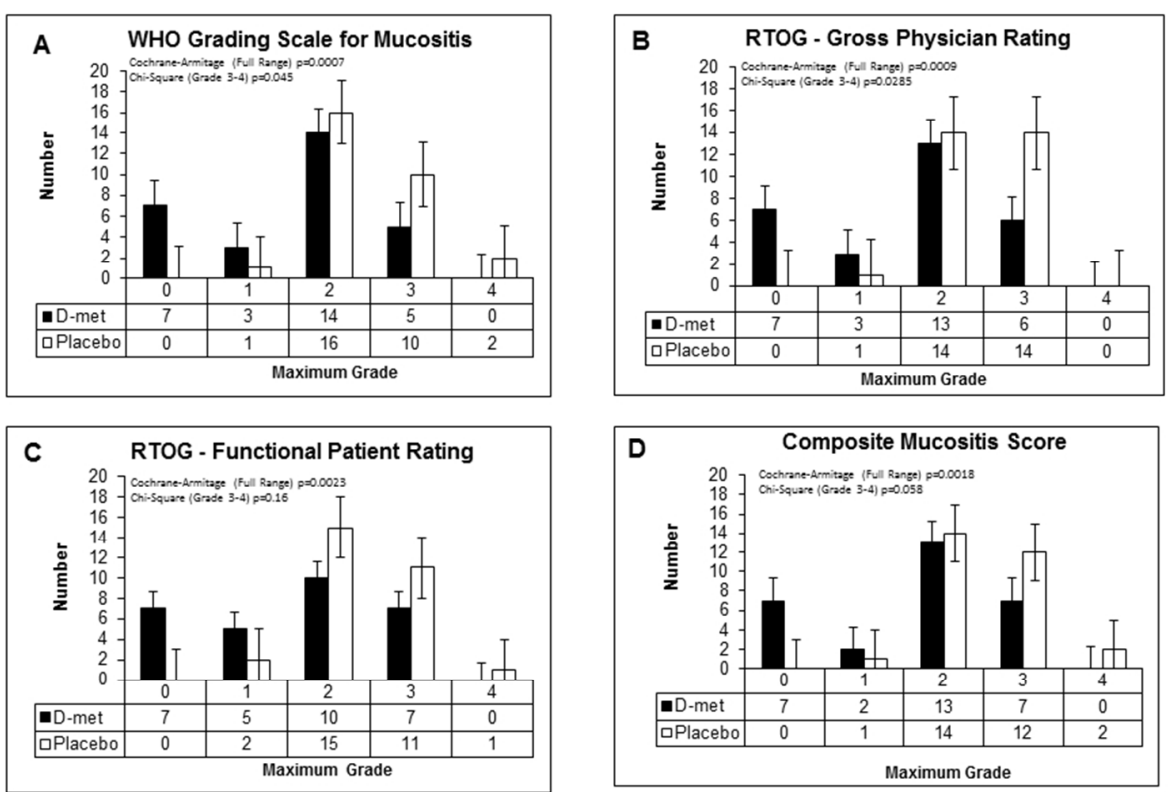

Figure 2

$254 \times 190 \mathrm{~mm}(96 \times 96 \mathrm{DPI})$

John Wiley \& Sons, Inc.

This article is protected by copyright. All rights reserved. 

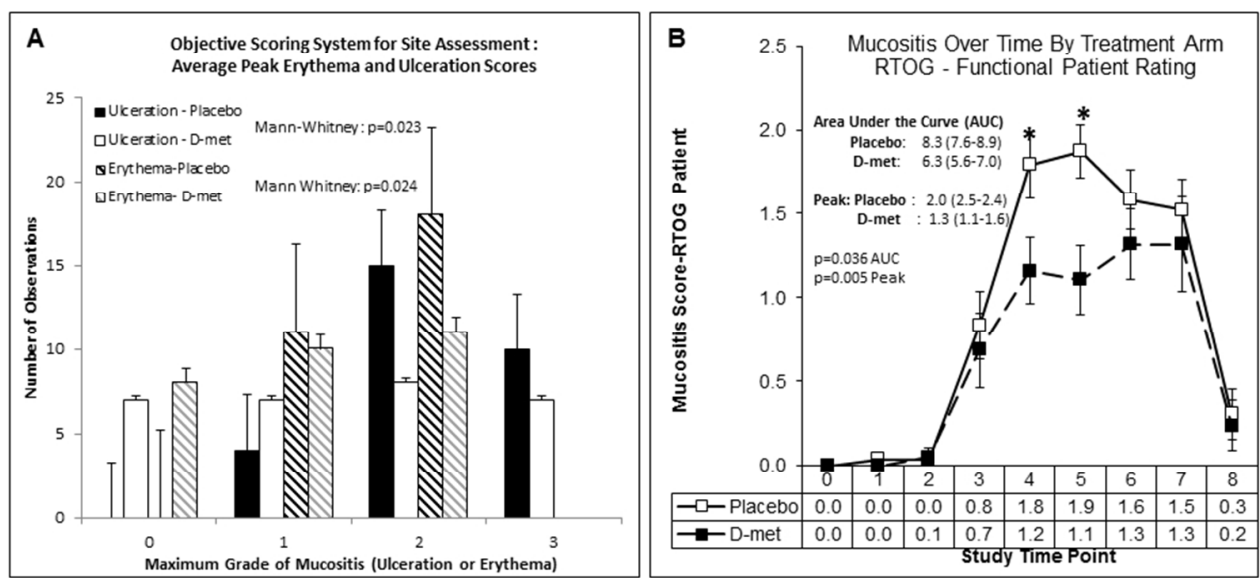

Figure 3

254x190mm (96 x 96 DPI)

John Wiley \& Sons, Inc. 


\section{Inclusion Criteria:}

- Histological confirmation of head and neck cancer, first occurrence;

- Medically suited to receive primary treatment with radiation and cisplatin;

- 18-65 years;

- Radiation area should include a minimum of $50 \%$ of the oral pharynx, oral cavity, or both;

- Negative serum pregnancy test in females of child-bearing potential;

- $\mathrm{KPS}>60$;

- Able to provide written informed consent.

\section{Exclusion Criteria:}

- Pregnancy;

- Breast feeding;

- T1 and T2 glottic tumors;

- Prior radiation to the head and neck region or prior chemotherapy of any type;

- History of allergic or idiosyncratic reaction to methionine, amino acid mixtures, strength formulations, egg white, other proteins, food additives;

- Simultaneous enrollment in other clinical studies;

- Other immunocompromised states,

- Current oral mucosal lesions other than from direct involvement of the underlying head and neck cancer;

- Cryotherapy to the face, head and neck region;

- Current use of any of the following oral care preparations: amifostine, chlorhexidine, sucralfate, benzydamine.

\section{$\underline{\text { Supplemental Table } 1 \text { : Inclusion and Exclusion Criteria }}$}




\begin{tabular}{|c|c|c|c|c|c|c|c|c|c|}
\hline \multicolumn{10}{|c|}{$\begin{array}{c}\text { Supplemental Table 5. Summary of Patients with Abnormal Hematology Parameters, by Maximum Grade }{ }^{\mathrm{a}} \\
\text { Number (\%) of Patients }\end{array}$} \\
\hline \multirow[b]{3}{*}{$\begin{array}{l}\text { Laboratory } \\
\text { Parameter }\end{array}$} & \multicolumn{3}{|c|}{$\begin{array}{l}\text { D-methionine } \\
\left(\text { Number }=24^{\text {b }}\right)\end{array}$} & & \multicolumn{5}{|c|}{$\begin{array}{c}\text { Placebo } \\
\left(\text { Number }=28^{b}\right)\end{array}$} \\
\hline & & Grade & & & & & ade & & \\
\hline & 1 & 2 & 3 & 4 & $\mathbf{0}$ & 1 & 2 & 3 & 4 \\
\hline $\begin{array}{l}\text { White Blood Cell } 19(79.2) \\
\text { Count }\end{array}$ & $4(16.7)$ & $1(4.2)$ & 0 & 0 & $21(75.0)$ & $6(21.4)$ & $1(3.6)$ & 0 & 0 \\
\hline $\begin{array}{l}\text { Absolute } \\
\text { Neutrophil Count } 24(100) \\
\text { Nadir }\end{array}$ & 0 & 0 & 0 & 0 & 27 (96.4) & $1(3.6)$ & 0 & 0 & 0 \\
\hline $\begin{array}{l}\text { Platelet Count } \\
\text { Nadir }\end{array}$ & 0 & 0 & 0 & 0 & 26 (92.9) & $1(3.6)$ & $1(3.6)$ & 0 & 0 \\
\hline $\begin{array}{l}\text { Hemoglobin } \\
\text { Nadir }\end{array}$ & $12(50.0)$ & $4(16.7)$ & 0 & 0 & $9(32.1)$ & $14(50.0)$ & $5(17.9)$ & 0 & 0 \\
\hline
\end{tabular}

${ }^{a}$ The worst post-baseline test result was graded according to the CTCAE,v3.0

${ }^{b}$ The total number of patients reported in a treatment group reflects the number of patients who had $\geq 1$ post-baseline test conducted.

Supplemental Table 6. Summary of Patients with Abnormal Chemistry Parameters, by Maximum Grade ${ }^{a}$ Number (\%) of Patients

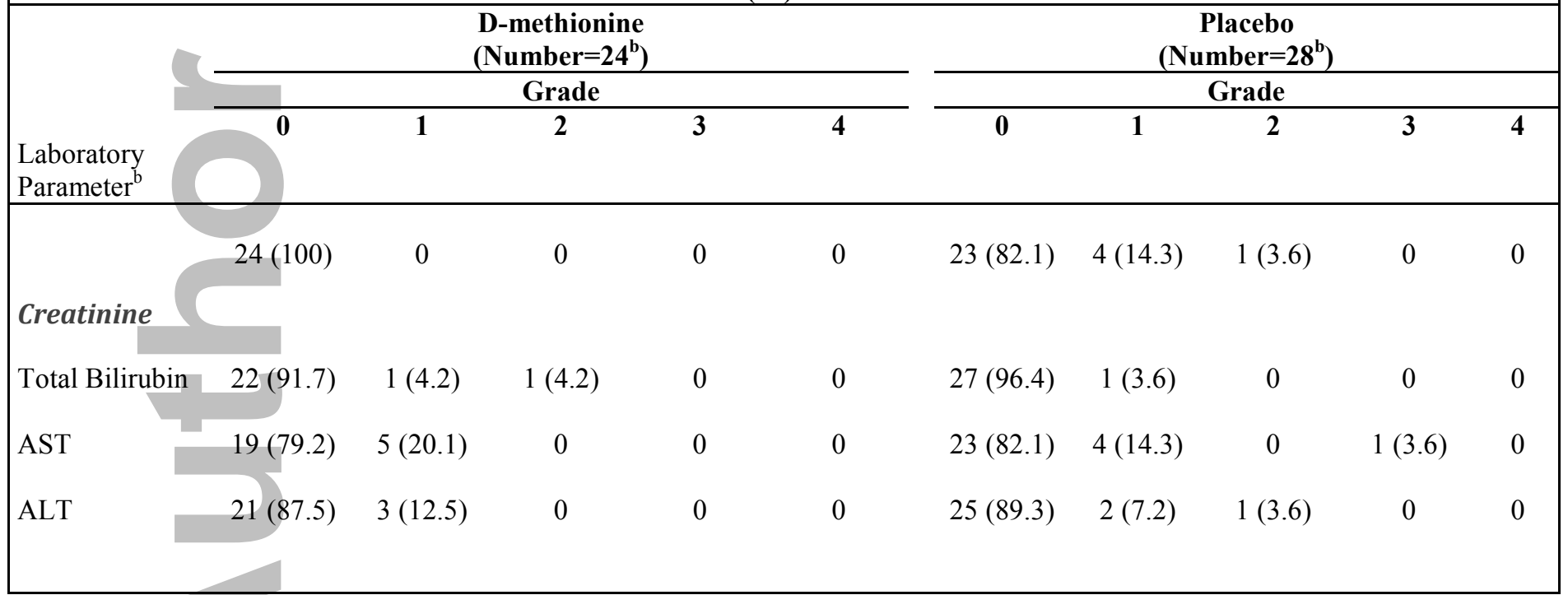

${ }^{a}$ The worst post-baseline test result was graded according to the CTCAE,v3.0

${ }^{b}$ The total number of patients reported in a treatment group reflects the number of patients who had $\geq 1$ post-baseline test conducted. 


\begin{tabular}{|c|c|c|c|c|c|c|c|c|c|}
\hline \multicolumn{6}{|c|}{\begin{tabular}{lc}
\multicolumn{2}{c}{ Supplemental Table 7. Summary of All Serious Adverse Ev } \\
& $\begin{array}{c}\text { D-methionine } \\
\text { (Number }=29)\end{array}$ \\
BODY SYSTEM & (Number
\end{tabular}} & \multicolumn{4}{|c|}{$\begin{array}{c}\text { stem and Treatment Group } \\
\text { Placebo } \\
(\text { Number }=29)\end{array}$} \\
\hline Term & $\begin{array}{c}\text { Total } \\
(\%) \\
\end{array}$ & $\begin{array}{c}\text { Grade } \\
2 \\
\end{array}$ & $\begin{array}{c}\text { Grade } \\
\mathbf{3} \\
\end{array}$ & $\begin{array}{c}\text { Grade } \\
4\end{array}$ & $\begin{array}{c}\text { Total } \\
(\%)\end{array}$ & Grade 2 & Grade 3 & Grade 4 & Grade 5 \\
\hline TOTAL PATIENTS ${ }^{\mathrm{a}}(\%)$ & $3(10.3)$ & $1(3.4)$ & $2(6.9)$ & 0 & $4(13.8)$ & 0 & $3(10.3)$ & 0 & $1(3.4)$ \\
\hline TOTAL SAEs & 11 & 2 & 9 & 0 & 13 & 4 & 6 & 2 & 1 \\
\hline HEMATOLOGIC & & & & & & & & & \\
\hline $\begin{array}{l}\text { Neutropenia/Leukopenia } \\
\text { Hemorrhage/ }\end{array}$ & 2 & 0 & 2 & 0 & 2 & 1 & 1 & 0 & 0 \\
\hline Thrombocytopenia & 1 & 0 & 1 & 0 & 1 & 1 & 0 & 0 & 0 \\
\hline Anemia & 2 & 1 & 1 & 0 & 1 & 0 & 0 & 1 & 0 \\
\hline DIGESTIVE & & & & & & & & & \\
\hline Dysphagia & 1 & 0 & 1 & 0 & 2 & 0 & 2 & 0 & 0 \\
\hline Anorexia & 1 & 0 & 1 & 0 & 1 & 0 & 1 & 0 & 0 \\
\hline Pain in Oral Cavity & 1 & 0 & 1 & 0 & 3 & 1 & 2 & 0 & 0 \\
\hline OTHER BODY SYSTEMS & & & & & & & & & \\
\hline Fatigue & 1 & 0 & 1 & 0 & 0 & 0 & 0 & 0 & 0 \\
\hline Edema & 1 & 1 & 0 & 0 & 0 & 0 & 0 & 0 & 0 \\
\hline Infection & 1 & 0 & 1 & 0 & 1 & 1 & 0 & 0 & 0 \\
\hline Dyspnea & 0 & 0 & 0 & 0 & 1 & 0 & 0 & 1 & 0 \\
\hline Hypotension & 0 & 0 & 0 & 0 & 1 & 0 & 0 & 0 & 1 \\
\hline
\end{tabular}

${ }^{a}$ Total Patients: Patients were counted once regardless of how many SAEs were reported in that patient. 


\begin{tabular}{|c|c|c|c|}
\hline \multicolumn{4}{|c|}{$\begin{array}{l}\text { Supplemental Table 8. Summary of Significant Protocol Deviations } \\
\text { [Number }(\%) \text { of Patients] }\end{array}$} \\
\hline Protocol Deviation & $\begin{array}{c}\text { D-met } \\
\text { Number }=29\end{array}$ & $\begin{array}{c}\text { Placebo } \\
\text { Number }=29\end{array}$ & p-value \\
\hline Pregnancy test not done during Baseline & $2(6.9)$ & $2(6.9)$ & $1.0^{\mathrm{a}}$ \\
\hline $\begin{array}{l}\text { CT scans not obtained: } \\
\text { at Baseline } \\
\text { at Follow-Up }\end{array}$ & $\begin{array}{l}4(13.8) \\
8(27.6)\end{array}$ & $\begin{array}{l}1(3.4) \\
6(20.7)\end{array}$ & $\begin{array}{l}0.35^{\mathrm{a}} \\
0.76^{\mathrm{a}}\end{array}$ \\
\hline $\begin{array}{l}\text { Hematology and chemistry tests not done at } \\
\text { Baseline }\end{array}$ & $4(13.8)$ & $4(13.8)$ & $1.0^{\mathrm{a}}$ \\
\hline Patient did not receive any doses of cisplatin & $4(13.8)$ & $4(13.8)$ & $1.0^{\mathrm{a}}$ \\
\hline Patient received carboplatin instead of cisplatin & $1(3.4)$ & $1(3.4)$ & $1.0^{\mathrm{a}}$ \\
\hline $\begin{array}{l}\text { Missed one or more doses of Study Medication } \\
\text { on days radiation was given }\end{array}$ & $7(24.1)$ & $2(6.9)$ & $0.079^{\mathrm{a}}$ \\
\hline $\begin{array}{l}\text { Patient received doses of } 5 \text {-fluorouracil in } \\
\text { addition to cisplatin chemotherapy }\end{array}$ & $11(37.9)$ & $12(41.4)$ & $1.0^{\mathrm{a}}$ \\
\hline
\end{tabular}

a=Fisher's exact test 


\begin{tabular}{|c|c|c|}
\hline \multicolumn{3}{|c|}{$\begin{array}{c}\text { Supplemental Table 9. Objective Response Rate via RECIST Criteria Based on } \\
\text { a Subset of } 29 \text { Patients with a Baseline CT Scan, a Follow-Up CT Scan, and } \\
\text { Measurable Disease at Baseline [Number (\%) of Patients] }\end{array}$} \\
\hline Response Category & $\begin{array}{l}\text { D-methionine } \\
\text { Number }=13\end{array}$ & $\begin{array}{c}\text { Placebo } \\
\text { Number }=16\end{array}$ \\
\hline Complete Response & $2(15.4)$ & $1(6.2)$ \\
\hline Partial Response & $4(30.8)$ & $9(56.2)$ \\
\hline $\mathrm{CR}+\mathrm{PR}$ & $6(46.2)$ & $10(62.5)$ \\
\hline
\end{tabular}




\begin{tabular}{|c|c|c|c|c|c|c|c|c|c|}
\hline & & $\begin{array}{c}\text { AUC }^{\text {all }} \\
\text { data }\end{array}$ & $\begin{array}{c}\text { AUC }^{\text {full }} \\
\text { data }\end{array}$ & p-value & $\begin{array}{c}\text { AUC } \\
\text { Protective } \\
\text { Factor } \\
\text { (all/full) }\end{array}$ & $\begin{array}{l}\text { Mean } \\
\text { Peak }^{\text {all }} \\
\text { data }\end{array}$ & $\begin{array}{l}\text { Mean } \\
\text { Peak }^{\text {full }} \\
\text { data }\end{array}$ & p-value & $\begin{array}{c}\text { Peak } \\
\text { Protective } \\
\text { Factor } \\
\text { (all/full) }\end{array}$ \\
\hline \multirow{2}{*}{$\begin{array}{c}\text { RTOG } \\
\text { Functional } \\
\text { Patient } \\
\text { Rating }\end{array}$} & Placebo & 8.3 & 7.6 & $\begin{array}{c}0.035 \\
\text { all }\end{array}$ & \multirow{2}{*}{$1.3 / 1.3$} & 2.0 & 1.9 & $\begin{array}{c}0.0056 \\
\text { all }\end{array}$ & \multirow{2}{*}{$1.5 / 1.4$} \\
\hline & D-met & 6.3 & 5.6 & $\begin{array}{c}0.036 \\
\text { full }\end{array}$ & & 1.3 & 1.3 & $\begin{array}{c}0.0048 \\
\text { full }\end{array}$ & \\
\hline \multirow{2}{*}{$\begin{array}{c}\text { RTOG Gross } \\
\text { Physician } \\
\text { Rating }\end{array}$} & Placebo & 8.9 & 8.3 & $\begin{array}{c}0.012 \\
\text { all }\end{array}$ & \multirow{2}{*}{$1.4 / 1.4$} & 2.0 & 2.0 & $\begin{array}{c}0.0014 \\
\text { all }\end{array}$ & \multirow{2}{*}{$1.4 / 1.4$} \\
\hline & D-met & 6.7 & 5.9 & $\begin{array}{c}0.034 \\
\text { full }\end{array}$ & & 1.4 & 1.4 & $\begin{array}{c}0.0014 \\
\text { full }\end{array}$ & \\
\hline \multirow{2}{*}{$\begin{array}{c}\text { WHO } \\
\text { Grading } \\
\text { Scale for } \\
\text { Mucositis }\end{array}$} & Placebo & 8.5 & 7.9 & $\begin{array}{c}0.017 \\
\text { all }\end{array}$ & \multirow{2}{*}{$1.4 / 1.4$} & 2.0 & 1.9 & $\begin{array}{c}0.002 \\
\text { all }\end{array}$ & \multirow{2}{*}{$1.5 / 1.4$} \\
\hline & D-met & 6.3 & 5.6 & $\begin{array}{c}0.038 \\
\text { full }\end{array}$ & & 1.3 & 1.3 & $\begin{array}{c}0.002 \\
\text { full }\end{array}$ & \\
\hline
\end{tabular}

The total time dependent response of mucositis to chemoradiotherapy with or without Dmet was evaluated (as seen for Figure 3A which was for the Functional Patient Scale from the RTOG scale) using all 3 scales. This score was calculated as the integral of mucositis over time and expressed as the Area Under The Curve (AUC). Given the secondary nature of the analysis it was performed in two ways.

First, there were nine time points at which mucosal evaluation was performed (baseline, weekly during RT for up to 7 weeks, and at 30 days post RT). For the time dependent analysis reported here a patient was included in the analysis only if mucosal evaluation was performed at a minimum 6 of 9 data points (Placebo: 24/29 patients and D-met: 20/29 patients which was not different between groups, Chi-square: $p=0.6$ ) this is reported as $\mathrm{AUC}^{\text {all }}$ or Peak ${ }^{\text {all }}$.

Second, analysis was also limited to those in whom all 9 data points were available which is reported as AUC ${ }^{\text {full }}$ and Peak ${ }^{\text {full }}$ (Placebo: 23/29 patients and D-met: 18/29 patients, Chisquare: $\mathrm{p}=0.5$ ).

The protective factor was calculated as the value for AUC or Peak mucositis score with Placebo divided by the score with $\mathrm{D}$-met where a value $>1.0$ would indicate lower mucositis with D-met.

Overall there was a higher AUC reflecting higher exposure to mucositis in the placebo arms on all three scales as compared to the D-met arm with protective factors of 1.3-1.4. Similarly, there were higher peak mucositis scores across all analyses for those treated with Placebo than those treated with D-met with protective factors of 1.4-1.5. No significant differences were noted between any of the scales. Comparisons for average AUC and average Peak were evaluated with student's t-test. 


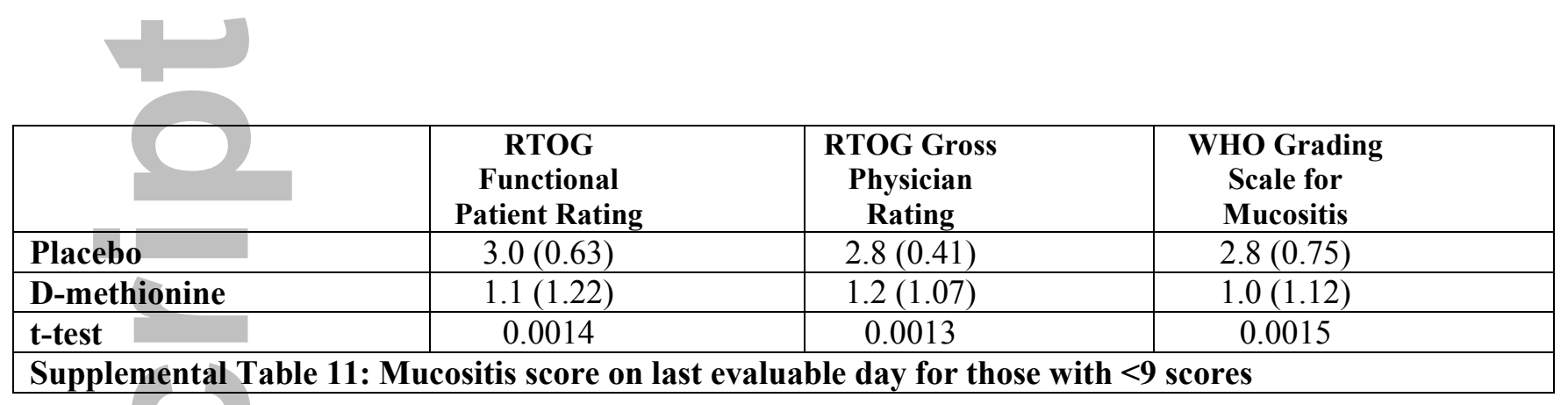
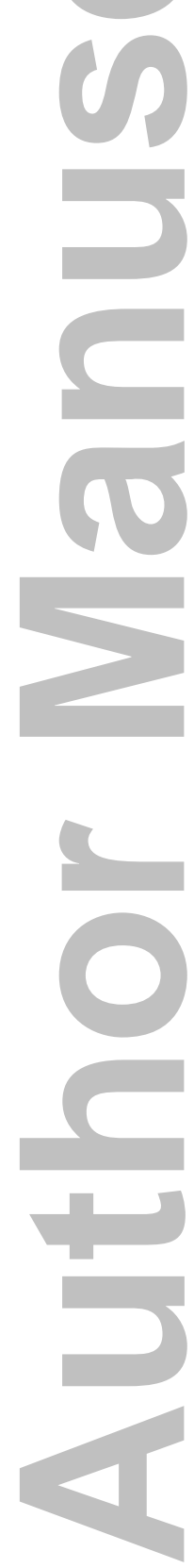


\begin{tabular}{|c|c|c|c|c|c|c|c|c|c|c|c|c|c|}
\hline \multicolumn{14}{|c|}{$\begin{array}{l}\text { Supplemental Table 12. Summary of Maximum WHO Oral Mucositis Scores } \\
\text { by Cumulative Radiation Exposure [Number of Patients] }\end{array}$} \\
\hline \multirow{3}{*}{$\begin{array}{c}\text { Cumulative } \\
\text { Radiation } \\
\text { Exposure } \\
\text { (Gy) }\end{array}$} & \multicolumn{5}{|c|}{ D-met $(N=29)$} & \multirow{3}{*}{$\begin{array}{c}\text { Grade } \\
\text { 3-4 } \\
\text { D-met }\end{array}$} & \multirow{2}{*}{\multicolumn{5}{|c|}{$\begin{array}{c}\text { Placebo }(\mathrm{N}=29) \\
\text { Grade }\end{array}$}} & \multirow{3}{*}{$\begin{array}{c}\text { Grade } \\
\text { 3-4 } \\
\text { Placebo }\end{array}$} & \multirow{3}{*}{$\begin{array}{c}\text { Overall } \\
\text { Grade } \\
3-4\end{array}$} \\
\hline & & & rad & & & & & & & & & & \\
\hline & & 1 & 2 & 3 & 4 & & 0 & 1 & 2 & 3 & 4 & & \\
\hline$<20$ & 3 & 0 & 0 & 0 & 0 & $\begin{array}{c}0 \% \\
(0 / 3)\end{array}$ & 0 & 0 & 0 & 1 & 0 & $\begin{array}{l}100 \% \\
(1 / 1)\end{array}$ & $\begin{array}{l}25 \% \\
(1 / 4)\end{array}$ \\
\hline $20-39$ & 1 & 0 & 2 & 0 & 0 & $\begin{array}{l}0 \% \\
(0 / 3)\end{array}$ & 0 & 0 & 1 & 0 & 1 & $\begin{array}{l}50 \% \\
(1 / 2)\end{array}$ & $\begin{array}{l}20 \% \\
(1 / 5)\end{array}$ \\
\hline $40-59$ & 0 & 2 & 3 & 1 & 0 & $\begin{array}{l}17 \% \\
(1 / 6)\end{array}$ & 0 & 0 & 3 & 4 & 0 & $\begin{array}{l}57 \% \\
(4 / 7)\end{array}$ & $\begin{array}{c}38 \% \\
(5 / 13)\end{array}$ \\
\hline $60-70$ & 3 & 1 & 9 & 4 & 0 & $\begin{array}{c}24 \% \\
(4 / 17)\end{array}$ & 0 & 1 & 12 & 5 & 1 & $\begin{array}{c}32 \% \\
(6 / 19)\end{array}$ & $\begin{array}{c}28 \% \\
(10 / 36)\end{array}$ \\
\hline Overall & 7 & 3 & 14 & 5 & 0 & $\begin{array}{c}17 \% \\
(5 / 29)\end{array}$ & 0 & 1 & 16 & 10 & 2 & $\begin{array}{c}41 \% \\
(12 / 29)\end{array}$ & $\begin{array}{c}29 \% \\
(17 / 58)\end{array}$ \\
\hline
\end{tabular}




\begin{tabular}{|l|c|c|}
\hline Supplemental Table 13: Grade 3-4 Mucositis as a Function of 5FU Use and D-met \\
\hline & Percentage with Grade 3-4 Mucositis Based on WHO Scale \\
\hline & $\underline{\text { No 5FU }}$ & $\underline{\mathbf{5 F U}}$ \\
\hline Placebo & $47.1 \%(8 / 17)$ & $33.3 \%(4 / 12)$ \\
\hline D-methionine & $16.7 \%(3 / 18)$ & $18.2 \%(2 / 11)$ \\
\hline
\end{tabular}

